\title{
Revisiting the Effect of Team Passion Displayed During National Anthems on Subsequent Success: A Replication and Extension
}

\author{
Harry Manley*, Trin Savejnarong, Pattramon Pornsukjantra, Mintra Bunditanukul \& Naravut \\ Sasipongsakorn
}

Faculty of Psychology, Chulalongkorn University

\section{Declaration of Conflict of Interest:}

The author(s) declared no potential conflicts of interests with respect to the authorship and/or publication of this article.

\section{Financial disclosure/funding:}

The author(s) received no financial support for the research.

\section{* Corresponding Author}

Harry Manley, Faculty of Psychology, Chulalongkorn University

harrisonmanley@gmail.com; https://orcid.org/0000-0001-9533-9207 
TEAM PASSION: REPLICATION AND EXTENSION

\begin{abstract}
Slater, Haslam \& Steffens (2018) found that the perceived level of team passion displayed during (pre-match) national anthems at UEFA Euro 2016 predicted team performance during the match. Teams that displayed greater passion conceded fewer goals and team passion predicted the likelihood of victory during the knockout (but not group) stages. Here, we replicate Slater et al. using a larger sample of matches from the FIFA World Cup $(n=415)$, and apply more appropriate analyses, and control for potential confounds. We also extend the original study to consider additional performance-related outcome variables (fouls, bookings, and possession). We found no empirical support for the effect of passion on performance outcomes. Supplementary materials, raw data and analysis files are available on the Open Science Framework (https://osf.io/q2urw).
\end{abstract}

Keywords: Passion, Social Identity, Team Performance, Replication 
TEAM PASSION: REPLICATION AND EXTENSION

\section{Revisiting the Effect of Team Passion Displayed During National Anthems on Subsequent Success: A Replication and Extension}

Research by Slater et al. (2018) demonstrated that the amount of team passion displayed during national anthems predicted subsequent performance outcomes for football teams during international competition. In an analysis of 52 matches during the UEFA Euro 2016, they found that anthem passion $^{1}$ (assessed via observers) was associated with fewer goals conceded throughout all stages of the competition. Further, anthem passion predicted the likelihood of a team winning, but only in the knockout (and not group) stage of competition. These results suggest that verbal and non-verbal indicators of team passion can be informative signals that predict how well the team will perform in an upcoming match.

The study described here is a close replication of Slater et al. (2018) and had two clear goals. The first goal was to conduct a close replication of the anthem passion effect in a larger sample, with more appropriate analysis that accounts for non-independence of observations and controls for potential confounds. The second goal of the current study was to examine extensions that consider additional performance metrics that may be predicted by team passion, (i.e., possession, fouls, expected goals).

We begin by introducing the literature on team passion and the chosen article for replication: Slater et al. (2018). Following that, we highlight the motivation for the current replication study. We then discuss the inclusion of additional variables that address potential confounds and extend the original findings.

\footnotetext{
${ }^{1}$ We use the term anthem passion throughout to indicate that team passion is being assessed by responses during the anthem.
} 
TEAM PASSION: REPLICATION AND EXTENSION

Anthem passion reflects the observation of verbal and non-verbal indicators of passion.

For example, a team that sings with gusto, stands tightly linked arm-in-arm, and looks intensely focused would demonstrate high anthem passion. In the original paper by Slater et al., anthem passion is proposed to be an observable indicator of the underlying level of team passion, and team passion is conceptualized as the collective amount of liking, interest, and investment that team members have towards their sport (Vallerand et al., 2003).

How might team passion benefit team performance? From a social identity approach, people can identify as individuals or as belonging to a social group (Tajfel \& Turner, 1979; Turner, 1982). In both organizational and sporting settings, there is robust evidence that group identification predicts group-based commitment and teams with strong (as opposed to weak) shared group identities demonstrate greater collective efforts (Christ et al., 2003; Knippenberg \& Schie, 2000; Rees et al., 2015; Slater et al., 2014). Passion for the group is closely associated with the strength of shared identity; thus, team passion may benefit performance via greater team-based commitment and effort (Fransen et al., 2016). Further, in the case of anthem passion, the verbal and non-verbal displays by players may serve as an additional communicative function that signals to the group that everyone is highly motivated and committed and this in turn increases team confidence and the willingness for individuals in the team to invest personal effort.

\section{Choice of Study for Replication}

We chose the current study based on the absence of any direct replications, the media interest in the effect, concerns about the small sample size, and potential for confounds in the measurement and analysis. To the best of our knowledge, there are no existing replications of this effect. Although the article has had modest impact to date on scholarly research in the field 
TEAM PASSION: REPLICATION AND EXTENSION

of social identity and sport psychology, these findings have received coverage in national media outlets (e.g., Independent). Slater et al.'s work also has important practical implications. For example, the effect suggests that the degree of passion at the anthem would enable one to predict the outcome of a match. However, the relatively small sample size of the original study makes it hard to draw reliable conclusions, especially regarding interaction effects with data from the knockout stage comprising only 30 games. Thus, it would be important to test this effect in a larger sample that is better powered to detect the presence of effects.

There are also important confounds that might undermine the original effect. First, it is unclear whether behavioral expressions displayed during the national anthem are a high-fidelity signal of team passion. In this regard it is possible for an athlete to feel (or not) a high degree of passion without necessarily displaying this during the anthem. This issue may be even more problematic given the cross-cultural nature of the samples and variance in the cultural norms for emotional expression across different countries. For example, players from Scandinavian countries are typically more reserved in their emotional displays than their Spanish or Italian counterparts (e.g., Tsai \& Chentsova-Dutton, 2003) and although this would lead to differences in perceptions of anthem passion, there may not be genuine differences in the underlying team passion.

Assuming that the signal from anthem passion is an accurate indicator of team passion, there remain some issues with the analytic approach of the original study. Most importantly, there are repeated observations of the same team within the tournament. Specifically, anthem passion and outcomes are measured for the same team on at least three occasions (for teams that are knocked out at the group stage) and a maximum of seven occasions for teams that reach the 
TEAM PASSION: REPLICATION AND EXTENSION

final. Thus, it's important to account for the non-independence of these observations within the analysis, an issue that was not addressed by Slater et al. in their original analyses.

To examine the anthem passion effect, we conducted a well-powered preregistered close replication of Slater et al. (2018). We aimed to test the replicability of this effect with an independent replication. This is especially important given the paucity of replication studies in the sport psychology literature.

\section{Original Hypotheses and Findings}

Slater et al. (2018) examined anthem passion for 102 teams across 52 matches during the UEFA Euro 2016 soccer tournament; hypotheses and findings are summarized in Table 1.

Table 1.

Summary of original findings in Slater et al. (2018).

\section{Effect}

$\begin{array}{lll}\text { Hypotheses } & \text { Analysis } & \text { Presence }\end{array}$

Main Effects

H1a. Goals Scored. Passion is positively correlated with goals scored

H1b. Goals Conceded. Passion is negatively correlated with goals conceded

H1c. Match Victory. Passion positively predicts victory

$\begin{array}{lcc}\text { Linear } & \text { No }(p>.05) & .00 \\ \begin{array}{l}\text { Regression } \\ \text { Linear }\end{array} & \text { Yes }(p<.05) & .04 \\ \begin{array}{l}\text { Regression } \\ \text { Logistic } \\ \text { Regression }\end{array} & \text { No }(p>.05) & .03 \\ & & \\ \begin{array}{l}\text { Linear } \\ \text { Regression }\end{array} & \text { No }(p>.05) & .02 \\ \begin{array}{l}\text { Linear } \\ \text { Regression }\end{array} & \text { No }(p>.05) & .02 \\ \text { Logistic } & \text { Yes }(p<.05) & .04 \\ \text { Regression } & & \\ \end{array}$

Interactions

H2a. Goals Scored. As game importance increased, so too would the strength of the relationship between passion and goals scored H2b. Goals Conceded. As game importance increased, so too would the strength of the relationship between passion and goals conceded H2c. Match Victory. As game importance increased, so too would the strength of the relationship between passion and victory 
TEAM PASSION: REPLICATION AND EXTENSION

\section{Replication and Extension}

We planned to replicate the original study design and test the same hypotheses (see Table 1). We replicate the original study using a larger sample with matches and anthems from the FIFA World Cups from 2006 - 2018. For a comparison of the original and replication design, see Table 2 .

Table 2.

Summary of original and replication study details.

\begin{tabular}{lll}
\hline & Slater et al. (2018) & Current Study \\
\hline Sample size & 102 anthems & 415 anthems \\
& UEFA Euro 2016 & FIFA World Cup \\
& & $2006,2010,2014,2018$ \\
Predictors & Anthem Passion & Anthem Passion \\
& Stage of Competition & Stage of Competition \\
Outcome & Goals Scored & Goals Scored \\
& Goals Conceded & Goals Conceded \\
& Match Outcome & Match Outcome \\
& & Possession \\
& & Fouls \\
Covariates & & xG (Expected Goals) \\
Analysis & & World Ranking \\
& & Linear Regression \\
& Linear Regression & Logistic Regression \\
& Logistic Regression & Linear Mixed Model \\
\hline
\end{tabular}

There were two main extensions to the original study. First, we examine the effect of anthem passion on alternative, and more nuanced, outcome measures: team possession, fouls committed, and bookings. We also run exploratory analysis examining whether passion predicted expected goals $(\mathrm{xG})$. Although winning a match is the ultimate aim $^{2}$ for any team, whether a

\footnotetext{
2 This may not always be true. For example, there are situations where a draw would be sufficient for a team to advance to the next round and in these cases not losing may be a more focal aim than winning.
} 
TEAM PASSION: REPLICATION AND EXTENSION

team wins or loses and how many goals they score and concede is often determined by a small number of chance events. In contrast, team possession reflects a performance indicator averaged over the entire match that may be a better measure of how well a team is playing. Because team passion is suggested to lead to greater commitment, we considered whether this may be observed in (more negative) outcomes related to the number of fouls a team commits and the number of bookings they receive. In addition, for a subset of matches from the 2018 World Cup, we also examined each team's expected goals $(\mathrm{xG})$, a metric based on the likelihood of a team scoring based on the chances they created.

A second extension in the current study was to analyze the data accounting for the repeated measurement. The original analysis used linear and logistic regression models that treated each measure of anthem passion as an independent observation. This is problematic because anthem passion is measured from the same teams on multiple occasions; there are at least three repeated measures from each team and up to seven observations for teams that reached the final. Here, we conducted additional analyses using linear mixed models that account for the nature of the data. Finally, to ensure that the effect of passion on performance is not confounded by differences in the strength of teams we also ran exploratory analyses controlling for the world ranking of each team.

\section{Method}

Data, materials, and analysis scripts are available on the Open Science Framework (https://osf.io/q2urw).

\section{Power Analysis.}

The sample size for the replication study was based on best-practice guidelines and pragmatic constraints. Because it is problematic to use effect sizes from previous results to determine the 
TEAM PASSION: REPLICATION AND EXTENSION

present sample size, the minimum sample size for the replication was justified based on the proposal that replication studies should use samples that are 2.5 times larger than the original sample (Simonsohn, 2015). Thus, because the original study sampled 102 anthems, this yielded a minimum target sample size of 255. In practice, we decided a priori to sample from as many anthems as were available online, this yielded a total of 415 anthem observations.

\section{Sample.}

The original study selected games from the Euro 2016 international football tournament. This included a sample of 24 teams competing in 51 matches and provided 102 observations of anthems. In the present study we extend this to analyse performance at the FIFA World Cup with anthems from matches during $2006(n=51), 2010(n=123), 2014(n=119)$, and $2018(n=$ 122). This yielded a total of 415 anthem observations from 56 different teams.

\section{Measures and Procedures.}

Footage of teams singing national anthems immediately before kick-off were accessed via footage uploaded to YouTube ${ }^{3}$. Each tournament included a maximum of 128 anthems, footage was not available for some teams during $2010(n=5), 2014(n=9)$, and $2018(n=6)$. During 2006, no footage was available for matches after the second game in the group stage (missing $n=77)$.

Anthem Passion. We assessed anthem passion using a similar approach as adopted by Slater et al. (2018). Two observers were provided with the definition of passion as "a strong inclination toward an activity that people like [or even love], that they find important, and in which they invest time and energy" (Vallerand et al., 2003, p. 757). Observers were asked to rate each team's passion during the singing of their national anthem on a scale from 1 (very low) to 9 (very

\footnotetext{
${ }^{3}$ https://www.youtube.com/channel/UC86DCET_rQTROaV35AJ3o6g
} 
TEAM PASSION: REPLICATION AND EXTENSION

high). The original paper used bounds from one to seven, we extended the bounds to allow for better discrimination in passion ratings. Observers were asked to watch each anthem and consider verbal and non-verbal indicators of passion. Verbal indicators included whether, and to what extent, each athlete engaged in singing (e.g., greater intensity indicates greater passion). Nonverbal indicators included the athletes' facial expression (e.g., the level of focus on athletes' faces) and body language (e.g., how closely the athletes stood together, the extent to which they put their arms around one another). To improve the reliability of ratings, we also asked observers to avoid reading any comments posted below the video, listen to the clips at a consistent volume, and judge passion from only the anthems and not any additional footage. In the original study, when observers were making their judgments of passion for each team, they were instructed to give an overall rating that averaged across perceptions of verbal and nonverbal cues. Thus, a team would be rated medium passion if they had high verbal cues and low non-verbal cues. In the replication study, we asked observers to assess each verbal and nonverbal cue individually. Thus, observers provided ratings for verbal passion, facial expressions, and body language. These individual ratings were then averaged to calculate a mean anthem passion score.

The observers were two psychology graduate students ${ }^{4}$. In cases $(n=7)$ where there was a disagreement of more than two points on any scale, the observers resolved the discrepancy by discussion and adjusted the mean score. For each rating of passion, we averaged across the observers' scores to create a single score for each team's anthem. In instances where a team did not display verbal passion because their anthem contained no lyrics, we coded these as missing responses and calculated the mean passion rating based on the non-verbal behaviours only. We

\footnotetext{
${ }^{4}$ Initially, four observers each rated half of the videos on a single measure of team passion, and without correcting any discrepancies. However, the inter-rater reliability was unacceptably poor and (after consultation with the lead author of the original paper) we re-rated the clips using the approach described in the text.
} 
TEAM PASSION: REPLICATION AND EXTENSION

assessed inter-rater reliability by examining the intraclass correlation coefficient for the mean item scores of anthem passion using the irr package in $R$. We calculated this for the unadjusted scores (i.e., the independent ratings before resolving any discrepancies), this indicated good correspondence between raters $(\mathrm{ICC}=.89[95 \% \mathrm{CI} .87-.91])$.

Stage of Competition. We coded the stage of competition as group or knockout. In total, across four tournaments there was anthem passion data from 321 games in the group stage (win/loss $n=$ 251; draw $n=70$ ) and 94 games in the knockout stages (win/loss $n=74$; draw $n=20$ ).

Goals and Game Outcome. We recorded goals scored and conceded by each team (including extra time), together with the outcome of the match (loss, draw, win). All match outcomes and statistics were recorded from an online database (https://fbref.com/).

Possession and Fouls. We recorded statistics of match possession (\%) and number of fouls committed. This data was only available for a subset of performances in the 2014 and 2018 World Cup $(n=177)$.

Expected Goals. As an indicator of performance that is less susceptible to chance and luck, we recorded $\mathrm{xG}$ (expected goals) for each team during matches played in the 2018 World Cup. This data was available for a subset of performances in the 2018 World Cup $(n=122)$.

Team Ranking. To index team ranking, we calculated each country’s FIFA world ranking points (https://www.fifa.com/fifa-world-ranking/men) at the start of the competition.

\section{Results.}

Replicating the original analysis, we first examined a hierarchical linear regression model to predict continuous outcome measures. Descriptive statistics of all measures are presented in Table 3. Statistical tests of the hypotheses are summarized in Tables 4-6 and plotted in Figure 1. 
TEAM PASSION: REPLICATION AND EXTENSION

Table 3.

Zero-order correlations for anthem passion during the group and knockout stages.

\begin{tabular}{lrrrr}
\hline & $\begin{array}{r}\text { Group Stage: } \\
\text { Anthem Passion }\end{array}$ & $n$ & $\begin{array}{r}\text { Knockout Stage: } \\
\text { Anthem Passion } \\
(r)\end{array}$ & $n$ \\
\hline Goals Scored & .11 & 321 & -.11 & 94 \\
Goals Conceded & -.02 & 321 & .11 & 94 \\
Possession & -.03 & 177 & .14 & 64 \\
Yellow Cards & -.10 & 321 & .09 & 94 \\
Fouls & .02 & 177 & .01 & 64 \\
xG & -.08 & 90 & -.05 & 32 \\
Team Ranking & .14 & 321 & .09 & 94 \\
\hline
\end{tabular}

Note. Adjusted $p$-values using Holm's method; no correlations were statistically significant.

The results of hierarchical linear regression models (Table 4) revealed that anthem passion was not a significant predictor of any outcome measure, and the effect of anthem passion was not moderated by the stage of competition.

We then examined an ordinal logistic regression model to predict team success. As shown in Table 5, this revealed that passion and competition stage were not statistically significant predictors of the match outcome. The interaction between passion and competition stage to predict match outcome was also not statistically significant. 
TEAM PASSION: REPLICATION AND EXTENSION

Table 4

Hierarchical linear regression analyses for passion predicting goals scored, goals conceded, possession, yellow cards, fouls and expected goals $(x G)$.

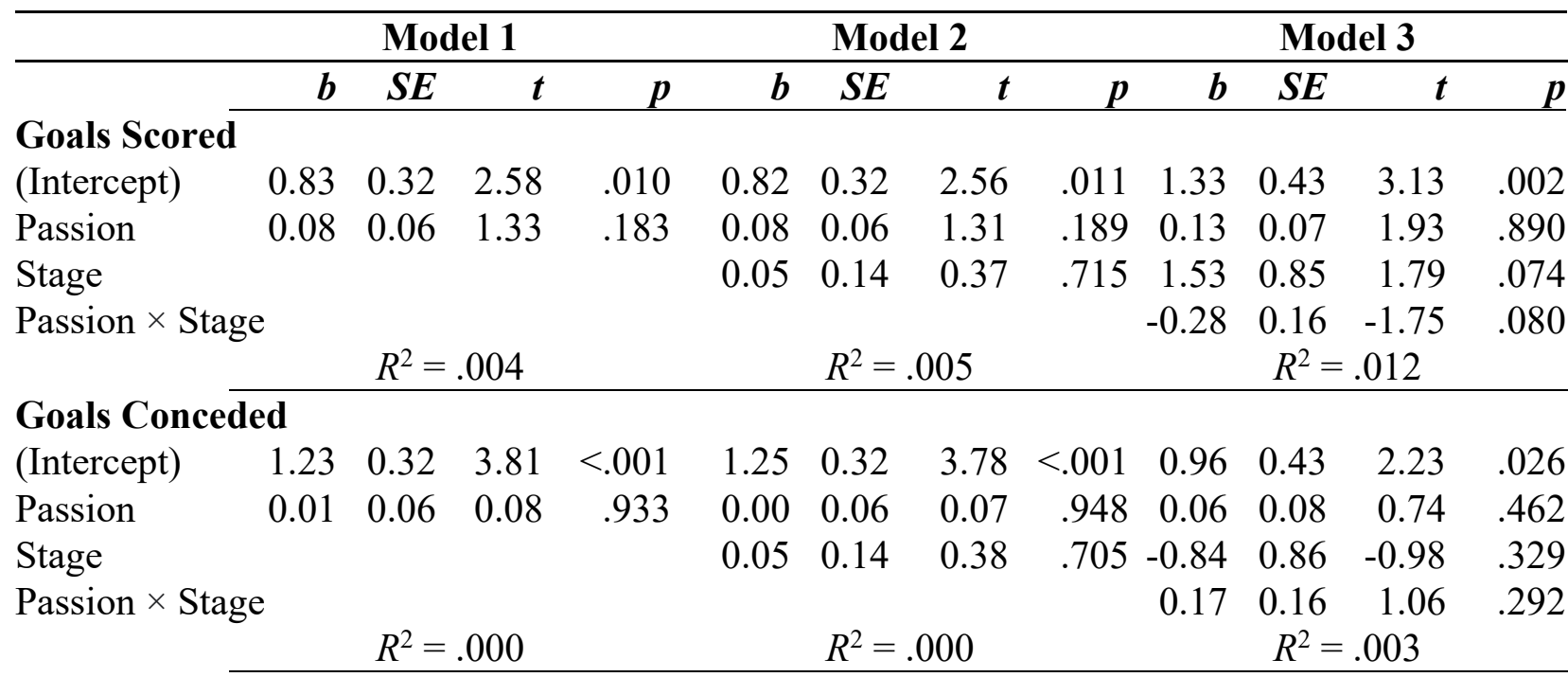

Possession

(Intercept)

$49.58 \quad 3.58 \quad 13.85<.001$

$49.57 \quad 3.59$

$13.80<.00147 .02$

$4.21 \quad 11.17<.001$

Passion

$0.09 \quad 0.65$

0.13

.894

$0.08 \quad 0.65$

$\begin{array}{lll}0.13 & .896 & 0.57\end{array}$

$\begin{array}{lll}0.77 & 0.74 & .461\end{array}$

Stage

$\begin{array}{lll}-0.05 & 1.55 & -0.03\end{array}$

$.974-9.67$

$\begin{array}{lll}8.42 & -1.15 & .252\end{array}$

Passion $\times$ Stage

$R^{2}=.000$

$\begin{array}{llll}1.79 & 1.54 & 1.16 & .246\end{array}$

Cards

(Intercept)

$\begin{array}{rrrr}2.21 & 0.35 & 6.32 & <.001 \\ -0.07 & 0.07 & -1.10 & .270\end{array}$

$R^{2}=.000$

$R^{2}=.006$

Passion $\begin{array}{llll}-0.07 & 0.07 & -1.10\end{array}$

$\begin{array}{ll}2.29 & 0.35\end{array}$

$6.25<.001$

1.81

$\begin{array}{rrr}0.46 & 3.90<.001\end{array}$

Stage

0.21

0.07

$-1.17$

$.244-0.13$

$0.07-1.74$

.083

Passion $\times$ Stage

$$
R^{2}=.003
$$

0.28

$\begin{array}{lll}0.93 & -1.36 & .175\end{array}$

Fouls

(Intercept)

$$
\begin{array}{ll}
14.76 & 1.67
\end{array}
$$

$\begin{array}{llll}8.83 & <.001 & 14.92 & 1.68\end{array}$

$R^{2}=.007$

$R^{2}=.014$

Passion

$0.04 \quad 0.30$

0.12

$\begin{array}{ll}0.07 & 0.30\end{array}$

$8.42<.00114 .94$

$0.24 \quad 808-0.07 \quad 0.36$

$\begin{array}{lll}1.95 & 7.66<.001\end{array}$

Stage

$\begin{array}{ll}1.56 & 0.72\end{array}$

2.17

$\begin{array}{lll}031 & 1.58 & 3.90\end{array}$

0.20

.842

Passion $\times$ Stage

$\begin{array}{lll}-0.01 & 0.71 & -0.01\end{array}$

$$
R^{2}=.000
$$

$R^{2}=.019$

$R^{2}=.019$

xG

$\begin{array}{lllllllllllll}\text { (Intercept) } & 1.83 & 0.42 & 4.33 & <.001 & 1.75 & 0.42 & 4.20 & <.001 & 1.80 & 0.59 & 3.03 & .003\end{array}$

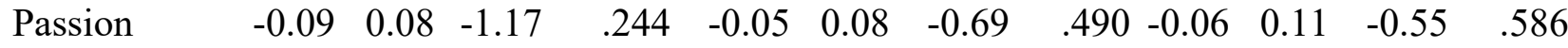

Stage

$\begin{array}{llllllll}0.48 & 0.20 & 2.44 & .016 & 0.61 & 1.18 & 0.52 & .605\end{array}$

Passion $\times$ Stage

$$
R^{2}=.011
$$

$-0.03 \quad 0.23 \quad-0.11$

Note. $b$ represents unstandardized regression weights. 
TEAM PASSION: REPLICATION AND EXTENSION

Figure 1.

Scatterplots of anthem passion as a predictor of outcome measure.
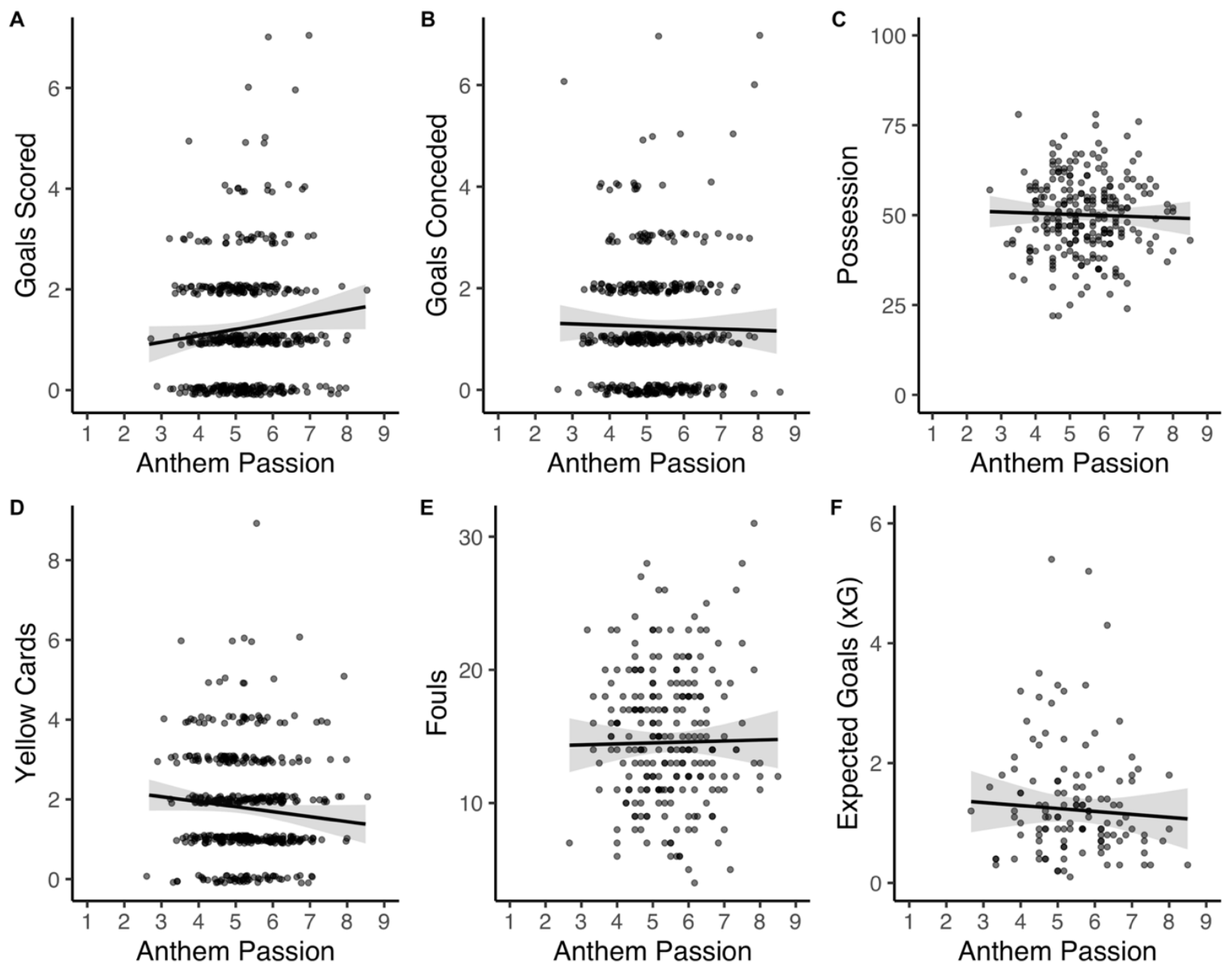

Note. Individual data points are plotted with a line of best fit. To aid visualisation, data points for goals scored, goals conceded, and yellow cards are jittered to avoid overlap. 
TEAM PASSION: REPLICATION AND EXTENSION

Table 5

Logistic regression analyses for passion predicting goals scored and conceded.

\begin{tabular}{lrrrrl}
\hline & $\mathrm{b}$ & $\mathrm{SE}$ & $\mathrm{Z}$ & $p$ & Odds Ratio $(95 \% \mathrm{CI})$ \\
\hline $\begin{array}{l}\text { Model 1 } \\
\quad \text { Passion }\end{array}$ & 0.04 & 0.09 & 0.48 & .630 & $1.05(0.87-1.25)$ \\
$\begin{array}{l}\text { Model } 2 \\
\quad \text { Passion }\end{array}$ & 0.04 & 0.09 & 0.48 & .630 & $1.05(0.87-1.25)$ \\
$\quad$ Stage & 0.00 & 0.22 & 0.00 & .997 & $1.00(0.65-1.54)$ \\
Model 3 & & & & & \\
$\quad$ Passion & 0.09 & 0.10 & 0.89 & .375 & $1.10(0.9-1.34)$ \\
$\quad$ Stage & 1.39 & 1.31 & 1.06 & .291 & $4.01(0.31-54.29)$ \\
$\quad$ Passion $\times$ Stage & -0.26 & 0.24 & -1.07 & .284 & $0.77(0.48-1.24)$ \\
\hline
\end{tabular}

Outliers. To explore the robustness of these effects, we reanalysed the data after removing games $(n=16)$ where teams either scored or conceded five or more goals. There was now a statistically significant interaction between anthem passion and competition stage to predict goals scored $\left(\beta=-0.29, t_{395}=-2.01 p=.045\right)$. The nature of this interaction indicated that passion was positively related to goals scored in the group stage (Simple slopes analysis: $\beta=0.09, p=$ $.14)$ but negatively related to goals scored in the knockout stage $(\beta=-0.20, p=.12)$. In addition, there was also a statistically significant interaction between anthem passion and competition stage to predict the number of yellow cards a team received $\left(\beta=0.36, t_{395}=1.97 p=.036\right)$. The nature of this interaction indicated that passion was negatively related to yellow cards in the group stage $(\beta=-0.13, p=.08)$ but positively related to yellow cards in the knockout stage $(\beta=-$ $0.23, p=.17)$.

Mixed Effects Model. A notable feature of the data in the original study and our replication is the non-independence of observations. Specifically, anthem passion and outcomes are measured for the same team on at least three occasions (for teams that are knocked out at the group stage) and a maximum of seven occasions for teams that reach the final. Consequently, we conducted 
TEAM PASSION: REPLICATION AND EXTENSION

additional analysis using a series of linear mixed effects models that can control for the repeated measurement of the teams.

We performed linear mixed-effects analysis using the lmer package in $R$. We conducted separate analyses for each outcome variable, in each model we examined the main and interaction effects of anthem passion and stage. When specifying the model, we began by attempting to fit a random slopes model and a model that included the tournament as a random effect; however, these models resulted in a singular fit. Consequently, we fit a model with teams as a random effect and with fixed slopes. This model is formalized as the following:

Outcome $\sim$ Anthem Passion + Stage + Anthem Passion $\times$ Stage $+(1 \mid$ Team $)$, where $\sim$ stands for "predicted from" and 1|Team refers to random intercept across teams.

These results are broadly consistent with the hierarchical linear regression models and illustrate that anthem passion was not a statistically significant predictor of most outcomes. The interaction effect between passion and tournament stage was not statistically significant at the traditional threshold $(p=.09)$; however, we examined how the effect of passion on goals scored varied as a function of tournament stage. A simple slopes analysis indicated that that there was a positive effect of passion on goals during the group stage $(\beta=0.14, p=.05)$ whereas there was no effect of passion on goals scored in the knockout stage $(\beta=-0.13, p=.37)$. 
TEAM PASSION: REPLICATION AND EXTENSION

Table 6.

Mixed effects model of passion, tournament stage, and their interaction effect to predict each outcome.

\begin{tabular}{|c|c|c|c|c|c|c|c|c|c|c|}
\hline \multirow[b]{2}{*}{ Predictors } & \multicolumn{2}{|c|}{ Goals Scored } & \multicolumn{2}{|c|}{ Goals Conceded } & \multicolumn{2}{|c|}{ Possession } & \multicolumn{2}{|c|}{ Yellow Cards } & \multicolumn{2}{|l|}{ Fouls } \\
\hline & $\begin{array}{l}\text { Estimate } \\
{[95 \% \mathrm{CI}]}\end{array}$ & $p$ & $\begin{array}{l}\text { Estimate } \\
{[95 \% \mathrm{CI}]}\end{array}$ & $p$ & $\begin{array}{l}\text { Estimate } \\
{[95 \% \mathrm{CI}]}\end{array}$ & $p$ & $\begin{array}{l}\text { Estimate } \\
{[95 \% \mathrm{CI}]}\end{array}$ & $p$ & $\begin{array}{l}\text { Estimate } \\
{[95 \% \text { CI] }}\end{array}$ & $p$ \\
\hline (Intercept) & $\begin{array}{c}1.15 \\
{[0.29-2.01]}\end{array}$ & .009 & $\begin{array}{c}0.95 \\
{[0.08-1.82]}\end{array}$ & .033 & $\begin{array}{c}47.97 \\
{[39.39-56.56]}\end{array}$ & $<.001$ & $\begin{array}{c}1.90 \\
{[0.96-2.84]}\end{array}$ & $<.001$ & $\begin{array}{c}14.51 \\
{[10.51-18.50]}\end{array}$ & $<.001$ \\
\hline Passion & $\begin{array}{c}0.00 \\
{[-0.16-0.16]}\end{array}$ & .974 & $\begin{array}{c}.0 .08 \\
{[-0.08-0.24]}\end{array}$ & .352 & $\begin{array}{c}0.15 \\
{[-1.37-1.68]}\end{array}$ & .844 & $\begin{array}{c}0.01 \\
{[-0.17-0.18]}\end{array}$ & .927 & $\begin{array}{c}0.16 \\
{[-0.57-0.89]}\end{array}$ & .669 \\
\hline Stage & $\begin{array}{c}1.31 \\
{[-0.35-2.97]}\end{array}$ & .123 & $\begin{array}{c}-0.79 \\
{[-2.47-0.36]}\end{array}$ & .358 & $\begin{array}{c}-10.47 \\
{[-25.06-4.11]}\end{array}$ & .159 & $\begin{array}{c}1.15 \\
{[-2.97-0.66]}\end{array}$ & .213 & $\begin{array}{c}1.17 \\
{[-6.47-8.80]}\end{array}$ & .764 \\
\hline Passion $\times$ Stage & $\begin{array}{c}-0.27 \\
{[-0.57-0.04]}\end{array}$ & .090 & $\begin{array}{c}-0.18 \\
{[-0.13-0.49]}\end{array}$ & .254 & $\begin{array}{c}1.60 \\
{[-1.10-4.29]}\end{array}$ & .245 & $\begin{array}{c}0.27 \\
{[-0.07-0.61]}\end{array}$ & .116 & $\begin{array}{c}0.09 \\
{[-1.32-1.49]}\end{array}$ & .905 \\
\hline \multicolumn{11}{|l|}{ Random Effects } \\
\hline$\sigma^{2}$ & 1.38 & & 1.41 & & 76.36 & & 1.65 & & 22.98 & \\
\hline$\tau_{00}$ & $0.10_{\text {Team }}$ & & $0.10_{\text {Team }}$ & & 39.25 Team & & 0.11 Team & & 1.29 Team & \\
\hline ICC & 0.07 & & 0.07 & & 0.34 & & 0.06 & & 0.05 & \\
\hline $\mathrm{N}$ & 56 Team & & 56 Team & & 44 Team & & 56 Team & & 44 Team & \\
\hline Observations & 415 & & 415 & & 241 & & 415 & & 241 & \\
\hline $\begin{array}{l}\text { Marginal R }{ }^{2} / \\
\text { Conditional } \mathrm{R}^{2}\end{array}$ & $0.01 / 0.08$ & & $0.01 / 0.07$ & & $0.01 / 0.35$ & & $0.03 / 0.08$ & & $0.02 / 0.07$ & \\
\hline
\end{tabular}

Note. Stage coded -0.5 (group) and +0.5 (knockout) 
TEAM PASSION: REPLICATION AND EXTENSION

Components of Passion. In another exploratory analysis, we also tested whether specific components of the anthem passion could predict our outcome variables. Specifically, we entered ratings of verbal passion, facial expressions, and body language as separate predictors in each model. Facial expressions of passion were positive predictors of team possession $(\beta=2.71$, $p=.027$ ) whereas (in direct contrast), passionate body language was a negative predictor of team possession $(\beta=-1.93, p=.024)$. None of the components of anthem passion were significant predictors of any other outcome measure (all $p$ values $>.05$ ). The only significant interaction effect was between body language and stage to predict expected goals $(\beta=0.38, p=.036)$; the nature of this interaction was such that the level of passion in body language during the group stages was unrelated to expected goals $(\beta=-0.04, p=.71)$, whereas body language passion was positively related to expected goals in the knockout stage $(\beta=0.34, p=.08)$. All other interaction effects were not statistically significant.

Team Quality and Passion. A potential confound of the original and current study is if there is an association between team quality and the country's disposition to display passion. In other words, is some other factor related to the country influencing both anthem passion and performance. For example, it could be that players from some countries (e.g., South America) are significantly more expressive and therefore score higher on behavioural cues for passion yet these same teams are also above average in their team ranking and therefore their performance outcomes are positive. To examine this, we calculated the zero-order correlation between individual ratings of team passion and FIFA world rankings of each team. This revealed a small, but statistically significant, positive correlation between anthem passion and world ranking $(r=$ $.14, p=.006)$. To control for the effect of team ranking, for each observation we calculated the difference of the FIFA world ranking between the teams playing each other, we then ran a 
TEAM PASSION: REPLICATION AND EXTENSION

follow-up analysis including ranking difference as a covariate in the model. This had no substantive effect on any of the results in the original analysis.

\section{Discussion}

Here, we replicated Slater et al.'s effort to examine whether the amount of passion a team displays during the national anthem can predict performance outcomes. In a larger sample of teams, we find little supporting evidence that anthem passion is a significant predictor of the number of goals scored, conceded, possession, yellow cards, fouls, and expected goals. Overall, these results suggest that anthem passion, as assessed by observer ratings of verbal and nonverbal behaviour, is not a good predictor of performance outcomes in competitive international soccer matches.

This does not mean that collective passion is not a predictor of performance outcomes. Instead, these null effects may reflect the fact that brief observations of verbal and non-verbal behaviour during a national anthem are poor indicators of collective passion. In this regard, one issue is whether the verbal and non-verbal behavioural cues are sufficiently relevant to collective passion. Another issue is whether the behavioural cues that would indicate collective passion are freely expressed and made observable during the national anthem ${ }^{5}$. In many ways, the national anthem is an optimal time to observe behavioural cues of collective passion because it represents a period of heightened emotions (i.e., where passion is likely to be most clearly displayed) and where players are required to stand next to each other, allowing for some standardisation in the assessment of behavioural cues across teams. However, it's also possible that behaviour is highly constrained for some teams/individuals, resulting in few observable signs of passion during the

\footnotetext{
${ }^{5}$ A broader limitation of the original study and the replication is that availability of cues is constrained by the focus of the television director. For example, the footage may disproportionately focus on players that are displaying the most passion or may be limited by focusing for extended periods on the crowd rather than the players.
} 
TEAM PASSION: REPLICATION AND EXTENSION

anthem. For example, Argentina's (shortened) anthem is an instrumental version that contains no lyrics, thus making it impossible for players to display verbal indicators of passion; other teams have each of their player's stand apart holding their hand over their heart; and there is significant variation in tempo, lyrics, and opportunity to display passion during different anthems. Thus, it is difficult to easily disentangle appropriate behavioural cues of passion when the cultural norms ${ }^{6}$ demand specific actions during the anthem.

Although the use of linear mixed models in the current study allowed us to account for the repeated measurement of teams, it is worth noting that there remain issues of nonindependence that are not addressed by this approach. Specifically, many observations of anthem passion and associated match outcomes are nested within the same match and require a more complex dyadic analysis to fully account for the structure of the data.

\section{Conclusion.}

In a large sample of international soccer matches, we find no evidence that anthem passion predicts performance outcomes. Thus, the available evidence suggests that behavioural cues of collective passion are not able to predict how teams perform in the subsequent match.

\footnotetext{
${ }^{6}$ It is notable that cultural variance in passion is more pronounced in the replication study (where we consider teams from around the world) as opposed to the original study (that only considered teams from within Europe).
} 
TEAM PASSION: REPLICATION AND EXTENSION

\section{References}

Christ, O., Dick, R., Wagner, U., \& Stellmacher, J. (2003). When teachers go the extra mile: Foci of organisational identification as determinants of different forms of organisational citizenship behaviour among schoolteachers. British Journal of Educational Psychology, 73(3), 329-341. https://doi.org/10.1348/000709903322275867

Fransen, K., Steffens, N. K., Haslam, S. A., Vanbeselaere, N., Vande Broek, G., \& Boen, F. (2016). We will be champions: Leaders' confidence in 'us' inspires team members' team confidence and performance. Scandinavian Journal of Medicine \& Science in Sports, 26(12), 1455-1469. https://doi.org/10.1111/sms.12603

Knippenberg, D., \& Schie, E. C. M. (2000). Foci and correlates of organizational identification. Journal of Occupational and Organizational Psychology, 73(2), 137-147. https://doi.org/10.1348/096317900166949

Rees, T., Alexander Haslam, S., Coffee, P., \& Lavallee, D. (2015). A Social Identity Approach to Sport Psychology: Principles, Practice, and Prospects. Sports Medicine, 45(8), 10831096. https://doi.org/10.1007/s40279-015-0345-4

Simonsohn, U. (2015). Small Telescopes: Detectability and the Evaluation of Replication Results. Psychological Science, 26(5), 559-569. https://doi.org/10.1177/0956797614567341

Slater, M. J., Coffee, P., Barker, J. B., \& Evans, A. L. (2014). Promoting shared meanings in group memberships: A social identity approach to leadership in sport. Reflective Practice, 15(5), 672-685. https://doi.org/10.1080/14623943.2014.944126

Slater, M. J., Haslam, S. A., \& Steffens, N. K. (2018). Singing it for “us": Team passion displayed during national anthems is associated with subsequent success. European 
TEAM PASSION: REPLICATION AND EXTENSION

Journal of Sport Science, 18(4), 541-549.

https://doi.org/10.1080/17461391.2018.1431311

Tajfel, H., \& Turner, J. (1979). An integrative theory of intergroup conflict. In W. G. Austin, \& S. Worchel (Ed.), Ntergroup relations: Essential readings (pp. 33-37). Brooks/Cole.

Tsai, J. L., \& Chentsova-Dutton, U. (2003). Variation among European Americans in Emotional Facial Expression. Journal of Cross-Cultural Psychology, 34(6), 650-657. https://doi.org/10.1177/0022022103256846

Turner, J. (1982). Towards a cognitive redefinition of the social group. In H. Tajfel (Ed.), Social identity and intergroup relations (pp. 15-40). Cambridge University Press.

Vallerand, R. J., Blanchard, C., Mageau, G. A., Koestner, R., Ratelle, C., Léonard, M., Gagné, M., \& Marsolais, J. (2003). Les passions de l'âme: On obsessive and harmonious passion. Journal of Personality and Social Psychology, 85(4), 756-767.

https://doi.org/10.1037/0022-3514.85.4.756 